\title{
ISSN 1984-6835
}

\section{Editorial}

\section{TÍTULO: Conhecer, adaptar e não perecer}

Sempre que reflito sobre nossa responsabilidade como cientistas e cidadãos, eu chego a uma conclusão: precisamos fazer mais. Se trouxermos tópicos relevantes à vida, saúde e comunidade para perto da nossa realidade, podemos ver o quanto a área de química e ciências afins tais como farmácia, bioquímica e biotecnologia, é necessária, versátil, porém desafiadora. Um bom profissional deve possuir excelente conhecimento técnico e acadêmico, estar atento e saber se posicionar frente à questões relevantes da área. Ao mesmo tempo, ele precisa desenvolver habilidades tais como boa comunicação, pró-atividade e saber aplicar um conhecimento teórico em rotinas que exigem uma dinâmica prática e efetiva. Assim, eu gostaria de pontuar algumas demandas urgentes do mundo moderno, sejam elas relacionadas aos nossos microambientes, sejam aquelas envolvidas em questões de interesse global.

É de conhecimento de todos, por exemplo, a preocupação internacional acerca dos impactos das mudanças climáticas, que consiste em um dos maiores desafios do nosso tempo. Neste contexto, podemos facilmente reconhecer os processos químicos relacionados aos mecanismos ou efeitos causados pelo aumento da concentração de $\mathrm{CO}_{2}$ na atmosfera, aumento da temperatura média e as consequências de eventos extremos tais como períodos de seca, ondas de calor e inundações. No entanto, um estudo recente realizado por um grande consórcio mundial mostrou, por exemplo, que apesar de se conhecer os efeitos do aquecimento global sobre as florestas a curto prazo, muito pouco se sabe sobre impactos a longo prazo. Fatores como a fragmentação florestal pela ação antrópica e o aumento da temperatura global poderiam levar o status de destruição de florestas tropicais de forma irreversível.

Consequentemente e, de forma geral, os impactos negativos das mudanças climáticas, se estendem a diversos setores da vida terrestre e utilização de recursos naturais, o que inclui a biodiversidade e serviços ecossistêmicos. Paralelamente, tais eventos causam sérias perdas em muitas culturas alimentares em todo o mundo, considerando tanto produtividade quanto qualidade nutricional.

Isto nos conduz a outro assunto igualmente pertinente, que é a segurança alimentar e a produção sustentável de alimentos para atender as necessidades de uma população cada vez maior. Dados da Organização para Alimentação e Agricultura (FAO) indicam que para atender à exigência global por alimentos e nutrição, a produtividade das lavouras deve dobrar até 2050. No entanto,

\footnotetext{
* Universidade de São Paulo, Departamento de Física e Química, Faculdade de Ciências Farmacêuticas de Ribeirão Preto, Av. do Café s/n, CEP 14040-903, Ribeirão Preto-SP, Brasil

Max Planck Institute for Molecular Plant Physiology. Am Mühlenberg 2, 14476, Potsdam, Germany

E-mail: paulabueno@yahoo.com
}

devido à natureza imprevisível e dinâmica das mudanças nas condições climáticas globais, o cenário de produtividade das lavouras disponíveis não é promissor. Em 2080, espera-se que a produtividade de muitas safras diminua cerca de $50 \%$ em muitas partes do mundo.

No catálogo de questões urgentes para a pesquisa científica e para a sociedade como um todo, é importante mencionar tópicos em biossegurança, haja vista o que temos presenciado de forma tão trágica e impactante, que é a pandemia causada pelo vírus SARS-CoV-2. Isto inclui também os inerentes desdobramentos econômicos e sociais. É evidente a necessidade de ser rever políticas públicas de investimentos e mecanismos para a manutenção de estruturas e parques de pesquisa preparados para fornecer rápida reposta à eclosão de catástrofes.

Da mesma forma, inclui-se também o planejamento de ações e protocolos de contenção de epidemias e/ou agentes tóxicos, por exemplo. Ou seja, precisamos ter em mente que, além de prevenir, é necessário também adaptar-nos às novas realidades em todos os níveis da vida humana e nas inter-relações com o meio ambiente. Sob uma outra perspectiva, o que vemos hoje é um exemplo do que as sociedades modernas deverão enfrentar nos próximas décadas e séculos.

Por fim, mesmo em meio a tantas demandas de pesquisa relacionadas aos exemplos pontuados aqui, é importante termos em mente que, além de cientistas, somos profissionais, cidadãos e formadores de opinião. Perguntas como: para que, como, para quem, e com quais recursos fazemos pesquisa devem ser constantemente repensadas e consideradas para que de fato, consigamos contribuir efetivamente para o nosso futuro e para o futuro deste extraordinário planeta em que vivemos. Temos muito a fazer, não podemos perecer e para tanto, gerar e compartilhar o conhecimento é fundamental.

Paula C. P. Bueno*

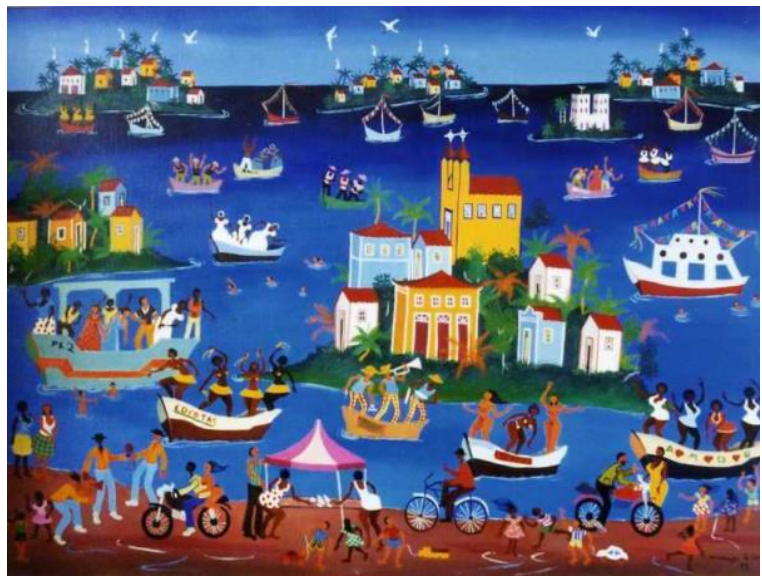

Capa: Esta obra é de autoria de Menezes de Souza (CE, RJ) intitulada "Carnaval em Angra" (1989), óleo s/ tela. $80 \mathrm{~cm}$ x $60 \mathrm{~cm}$. Coleção particular de Etelvino Bechara.

DOI: $\underline{10.21577 / 1984-6835.20200064}$ 